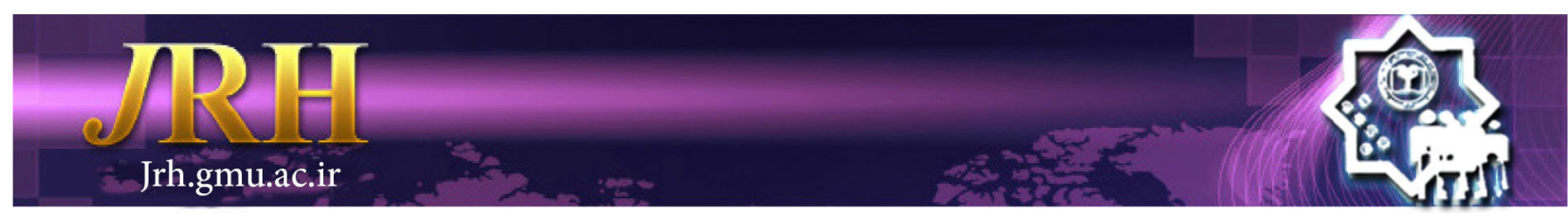

\title{
Effect of attachment-based therapy training on intimacy and alexithymia in parents of children with intellectual disabilities
}

Amir Ghamarani ${ }^{1}$, Hamed Ghasemi Arganeh ${ }^{2}$, Samad Azimi Garosi ${ }^{3}$, Mohamad Ghasemi Arganeh ${ }^{4}$

\author{
Journal of Research \& Health \\ Social Development \& Health Promotion \\ Research Center \\ Vol. 9, No.1, Jan \& Feb 2019 \\ Pages: 3- 10 \\ DOI: $10.29252 / j r h .9 .1 .3$ \\ Original Article
}

1. Department of Psychology of Children with Special Needs, Faculty of Education and Psychology, University of Isfahan, Isfahan, Iran

2. Correspondence to: Department of Counseling, Faculty of Psychology, University of Isfahan, Isfahan, Iran

Email: hamed2186@yahoo.com

3. Department of Psychology of Children with Special Needs, Faculty of Education and Psychology, University of Tehran, Tehran, Iran

4. Department of Special Education, Faculty of Education and Psychology, Teachers University of Allameh Amini, Tabriz, Iran

Received: 21 Feb 2013

Accepted: 13 Jun 2015

How to cite this article: Ghamarani A, Ghasemi Arganeh H, Azimi Garosi S, Ghasemi Arganeh M. Effect of attachmentbased therapy training on intimacy and alexithymia in parents of children with intellectual disabilities. $J$ Research \& Health2019; 9(1): 3- 10 .

\begin{abstract}
Parents of children with Intellectual Disabilities obviously and undeniably experience the same love and joy for their children, but they also have an increased risk of encountering stressors (e.g., high medical costs), anxiety, and depression. The present study was conducted with the aim of investigating the effect of attachment-based therapy training on increasing intimacy and alexithymia of the parents of intellectual disabilities children. 30 parents were randomly selected. They were then randomly divided into two groups. The experimental group participated in 8 sessions of attachment-based therapy and control group received no intervention. The research design was quasi-experimental. The research findings revealed a significant difference between the experimental group and the control group concerning the degree of intimacy. However, no significant contrast was found in terms of the Alexithymia. With respect to findings of the current study, it can be concluded that training based upon the attachment style can lead to intimacy increase among parents of mentally retarded children.
\end{abstract}

Keywords: Alexithymia, Attachment, Intellectual Disability, Intimacy, Parenting

\section{Introduction}

Marriage, as the most important and supreme social practice for individuals to achieve their emotional needs, has always been emphasized. Marriage is a human, complex, fine, and dynamic relationship enjoying special features. Main reasons for marriage are considered as love and affection, having a partner in life, the satisfaction of affective-emotional needs, and enhancement of intimacy and happiness [1]. Therefore, couples' symbiosis puts them in a circle of different interactions not comparable with other patterns of human relationships [2]. Intimacy is the main feature which is inseparable from couples' and families' lives. In fact, intimacy distinguishes family from other social groups [3]. Intimacy is a broad concept covering discussions about details of life to enclosure of the most private sexual feelings which somebody cannot easily speak of. Intimacy refers to having a close and friendly relationship usually with an affective, lovely, and personal relationship 
with somebody else which requires detailed information or profound knowledge of him or her [4]. Intimacy between couples is the secondary product of attentions, acceptance, sensitivity, and understanding. Therefore, by losing intimacy, one of the connections of a marital life is removed [5]. Scientific studies conducted on intimate relationships, as an important aspect of marital life, started in 1960's by Miller et al., [6] and Bagarozzi identified and investigated its dimensions by more than 30 years study of couples [7]. Many studies have indicated that having intimate relationships is effective on reducing depression and anxiety as well as enhancing mental health [8]. Intimacy, considered as a significant process in improving friendly relationships, is currently the main concern for experts of counseling, marriage and family. Technological, cultural, economic, and social changes as well as transformations in religion have been significantly effective on the initial functions of marriage which are love, affection, and closeness of couples [9].

Among changes that can endanger couples' intimacy is the birth of disabled children. It has been identified that when parents get compatible with having a disabled child, may gradually suffer from alexithymia [10]. This issue is more evident in parents with mentally retarded children than those with other types of disability in that those parents always present their children's academic successes as their own honorary index; thus the birth of a disabled child can devastate their parents' palace of desires about their children's academic and career achievements [11]. The term alexithymia was introduced by Sifneos [12] for describing psychological disabilities in identifying and expressing emotional aspects. In addition, alexithymia refers to the difficulties in emotional self-regulation, or in other words, disability in cognitive processing of emotional information as well as emotional regulation. Alexithymia is also defined as a set of cognitive and emotional deficits in expressing, describing and identifying, and differentiating feelings [13]. Individuals suffering from alexithymia are mostly identified with an imaginative life with inner and disinhibited emotions [14]. Formerly, alexithymia was mainly considered as a clinical tableau of psychosomatic disorders [12], but nowadays, it has been identified that alexithymia is also related to other life conditions such as depression, emotional disorders [15], eating disorders [16], childhood abuse, and other traumatic events [17]. Maganc and Burgette [18] indicated that emotional disability is related with low levels of emotion and relations with others, failure to express ones' own problems with others, and coping strategies in personal situations.

Moreover, another variable with a fundamental role in the enhancement or reduction of couples' intimacy and alexithymia is the attachment style [19-21]. John Bowlby conducted broad studies on the concept of attachment for the first time and described it as the stable psychological relationship and bond between two human beings [22]. Research conducted on quality of attachment can be divided into two main groups of child-mother attachment, including secure attachment and insecure one. Insecure attachment is of three types: avoidant insecure attachment, resistant insecure attachment, and ambivalent insecure attachment. According to Bowlby, Blehar, Waters, and Wall's theory, three types of secure, avoidant, and ambivalent attachment styles can be described in children. These attachment styles were also confirmed in adults [23]. All in all, individuals with secure attachment styles experience lower conflicts, more satisfaction, more intimacy, and more durability in their romantic relationships, while individuals with insecure attachment styles suffer from more conflicts, lower satisfaction, and lower durability and shorter periods in their romantic relationships [20]. Generally speaking, the results of studies indicate that individuals' attachment styles is an confident predictor for explaining their differences in psychological dimensions, social attachment, social cognition, romantic and martial relationships, the degree of control over stresses and emotions, reactions 
to separations, efficiency in interpersonal relationships, schemas of individuals about themselves and others [21], and marital intimacy and satisfaction [19].

Attachment-based therapy is a term used for interventions or approaches based on attachment theory, originating from Bowlby's theory. These approaches are in a range of methods of personal therapy to public health programs specifically designed for families with adopted children [24]. Kauhanen et al, [25] did a broad study on middle-aged men and found out that there is a correlation between alexithymia and bachelorhood. Weinrib et al, [26] indicated that there is a correlation between alexithymia and fear of avoidance of intimacy in BA/BSc students. Kokkonen et al., [27] found out that divorced individuals and bachelors suffer from alexithymia more than other groups. Humphries et al., [13] observed a correlation between alexithymia and low satisfaction with sexual relations. With regard to the mentioned results, it seems that parents of children with intellectual disabilities are more prone to suffering from alexithymia than other parents because parents of mentally retarded children face difficulties in making social relationships more than other parents and consequently they are more prone to alexithymia than other parents. Therefore, it was identified that Parents of children with Intellectual Disabilities are more prone to experiencing despair, loneliness, fear, anger, infertility, frustration, destruction, shock, sadness, anxiety, and worry than other parents. These negative feelings are reported for intellectual disabilities children by their mothers and fathers in a repetitive way $[28,29]$. Some studies also indicated the effect of attachmentbased therapy. For example, Botlani Esfahani [30] found out that attachment-based couple therapy does not change couples' attachment style, but their sexual satisfaction and intimacy increase significantly. Whitelather and Doumas [31] indicated in their research that attachmentbased therapy is very effective for preventing interpersonal problems and sexual intimacy and behaviors. Regarding the innovative nature of attachment-based therapy and abundant effects of couples' intimacy on their lives, the aim of the present study was to probe the effect of training the attachment style on intimacy and alexithymia of parents of children with intellectual disabilities.

\section{Method}

The population of the present study consisted of all Parents of children with Intellectual Disabilities in Kermanshah city in northwest portion of Iran, 2015. First, all parents of children with special needs, then only parents with children studying in schools under the education organization, and finally, those parents with intellectual disability were selected via the multistage stratified random sampling method. As a result of this sampling, 30 parents were recruited and divided into two equal groups of control and experimental. Participants in the two groups were compared by a pretest (the Intimacy and Alexithymia Inventory). It should be noted that since the research design was quasi-experimental, the sample size with 15 participants was sufficient [31]. In addition, according to table 4 and investigating the statistical power, it was identified that the present sample size had acceptable sufficiency [32].

The experimental group participated in 8 sessions of training courses each took 1.5 hours. In those sessions, training the attachment styles was conducted based on the suggested program of Whitelather and Doumas [33]. Training was conducted 2 sessions per week in an agreement with the group members. Other than the first session, the schedule was that first of all tasks related to the previous session were investigated and members represented their feelings and behaviors of the previous sessions to each other and received feedbacks. In addition to accomplishment of some tasks out of sessions, some skills were accomplished during sessions. At the end of each session, tasks appropriate to the subject of the session were introduced in order that the members accomplish them in the interval between the two sessions (headings and contents of sessions are represented in Table 
1). At the end training sessions, two groups were compared using the intimacy and alexithymia inventory as posttest and the obtained results were analyzed using SPSS-18.

\begin{tabular}{ll} 
Table 1 Headings and contents of training attachment-based therapy sessions \\
\hline Therapy sessions & Session contents \\
\hline Session 1 & Referrals and explanation about the logic of training attachment-based therapy \\
Session 2 & Attachment and its formation in the life cycle \\
Session 3 & Introducing different dimensions of attachment and its characteristics \\
Session 4 & Unhealthy dependence and the way to get healthy independence \\
Session 5 & Explanation, changes and flexibility of attachment styles \\
Session 6 & Explanation, changes and flexibility of attachment styles \\
Session 7 & The role of attachment and alexithymia in the marital life \\
Session 8 & Review of skills already learned and training skills of maintenance and continuity
\end{tabular}

The Marital Intimacy Questionnaire (MIQ): This questionnaire, developed by Olia et al, includes 85 items scaled via five point Likert scale with 1 representing "never" and 4 representing "always". Its validity was confirmed by five counseling experts of Faculty of Psychology at University of Isfahan. To investigate concurrent validity of the questionnaire, Walker and Thompson's Intimacy Scale was used; thus the results indicated that the correlation between the two questionnaires was 0.92 at the significance level of 0.01 . Cronbach's $\alpha$ was employed for determining reliability and 0.98 was obtained confirming the reliability of the questionnaire. The scoring method was via the sum of scores of items in such a way that the minimum score was 85 and the maximum was 340 . We consumed that the higher the score a participant obtained, the higher marital intimacy he/she had [34].

Toronto Alexithymia Scale (TAS-20): The other research instrument was the 20-item Persian version of the Toronto Alexithymia Scale (TAS-20) developed by Bagby et al., [35] who calculated the reliability of the scale as 0.81 via Cronbach's $\alpha$ and test-retest technique as 0.77. In Iran, the TAS-20 was translated and validated in two separate studies on a group of addicts [21] as well as clinical and nonclinical groups [35]. In the first study [37] conducted on 321 male and female addicts, the reliability value ranged from 0.71 to 0.83 via Cronbach's $\alpha$ for subscales and the total score of the scale. In addition, Cronbach's $\alpha$ coefficient ranged from 0.61 to 0.69 via the test-retest technique for 2 weeks. Validity of the scale was confirmed via concurrent validity of emotional intelligence scale and positive mental health scale. In the second study [35] conducted on 175 patients suffering from depression, anxiety, and obsessive - compulsive disorder and 173 healthy individuals, reliability of the scale was confirmed via Cronbach's $\alpha$ and testretest techniques. In addition, the results of factor analysis confirmed the three factor structure of the Persian version of the scale.

\section{Results}

The process of participants' presence in training sessions is described in Table 2. To investigate the significance of mean scores difference between two groups, MANCOVA was employed. In this analysis, the effects of the control variable and pretest were obtained out of posttest scores. Then, the two groups were compared with regard to the remaining scores. The results of Levene's test of the presumptions equality of variances in the two groups are presented in Tables 2, 3, and 4.

Table 2 The process of participants'presence in the pretest and posttest (per individual)

\begin{tabular}{cccccc}
\hline \multicolumn{4}{c}{ Pretest } & \multicolumn{3}{c}{ Posttest } \\
\hline Attachment style & Control & Total & Attachment style & Control & Total \\
\hline 15 & 15 & 30 & 15 & 15 & 30 \\
\hline
\end{tabular}


As observed in Table 2, the sample size as experimental groups; thus there is no reduction 15 participants is present at both control and

in the study groups.

Table 3 Results of Levene's test based on equality assumptions of variances in the two groups

\begin{tabular}{lcccc}
\hline Variables/indicators & f-value & Df 1 & Df 2 & Sig. \\
\hline Intimacy & 0.47 & 1 & 58 & 0.49 \\
Alexithymia & 2.05 & 1 & 58 & 0.15 \\
\hline
\end{tabular}

The results indicated that assumptions of ANCOVA have been observed.

To investigate the assumption of homogeneity of variances, Levene's test was employed and the results are presented in Table 3. As indicated, the value obtained for Levene's test was not significant; therefore, it can be concluded that variances are homogeneous and ANCOVA is possible.

As observed in Table 4, there is no significant difference between mean scores of the pretest and posttest of the control group. In addition, there is more difference between mean scores of pretest and posttest of the experimental group.
This issue indicates that the independent variable were effective on the experimental group. The issue worthy of noting is that the independent variable could increase intimacy and reduce alexithymia.

in according to Tables 3 and 4, the independent variable (training attachment styles) had significant effects on intimacy $(\mathrm{p} \leq 0.000)$, but it did not have any significant effects on alexithymia. The degree of effect of this variable on intimacy was $63 \%$ and on alexithymia was $3 \%$. In other words, there was a significant difference between the experimental and control group in terms of intimacy.

Table 4 Comparison of mean scores and SD in the Marital Intimacy and alexithymia scales of the two groups in the pretest and posttest

\begin{tabular}{lccccccccc}
\hline & & \multicolumn{3}{c}{ Experimental group } & \multicolumn{3}{c}{ Control group } \\
\cline { 3 - 9 } Variables & \multirow{2}{*}{ N } & \multicolumn{2}{c}{ Pretest } & \multicolumn{2}{c}{ Posttest } & \multicolumn{2}{c}{ Pretest } & \multicolumn{2}{c}{ Posttest } \\
\cline { 3 - 10 } & & Mean & SD & Mean & SD & Mean & SD & Mean & SD \\
\hline Intimacy & 30 & 150.1 & 3.95 & 161.4 & 3.82 & 152.1 & 3.18 & 153.8 & 3.01 \\
Alexithymia & 30 & 41.23 & 2.12 & 39.00 & 2.39 & 39.23 & 2.89 & 38.57 & 2.90 \\
\hline
\end{tabular}

Table 5 The effects of attachment-based interventions on marital intimacy and alexithymia of parents with mentally retarded children

\begin{tabular}{llccccccc}
\hline $\begin{array}{l}\text { Sources of } \\
\text { variations }\end{array}$ & $\begin{array}{l}\text { Indicators/ } \\
\text { variables }\end{array}$ & SS & df & MS & F & P & $\begin{array}{c}\text { Degree of } \\
\text { impact }\end{array}$ & $\begin{array}{c}\text { Statistical } \\
\text { power }\end{array}$ \\
\hline Pretest & Alexithymia & 213.50 & 1 & 213.50 & 79.75 & 0.000 & 79.75 & 1.000 \\
& Intimacy & 46.93 & 1 & 46.93 & 4.24 & 0.04 & 4.24 & 0.052 \\
\hline $\begin{array}{l}\text { Group } \\
\text { membership }\end{array}$ & Alexithymia & 8.13 & 1 & 8.13 & 3.03 & 0.08 & 3.03 & 0.40 \\
& Intimacy & 697.71 & 1 & 697.71 & 63.10 & 0.000 & 63.10 & 1.000 \\
\hline
\end{tabular}

Given that in Intimacy Scale, high scores indicate high intimacy, Tables 3 and 4 indicate that mean scores in the Intimacy Scale has increased for the experimental group indicating the effectiveness of the attachment-based therapy training on the degree of intimacy of parents with intellectual disability children, while the differences of pretest and posttest mean scores did not change significantly for the control group.

The aim of the present study was to investigate the effectiveness of attachment-based therapy training on intimacy and alexithymia of parents with intellectual disability children. The results indicated the effectiveness of attachment-based therapy training on parents with intellectual disability children. In other words, the independent variable, i.e. attachment-based therapy training was effective on intimacy $(p \leq 0.000)$, but it had no effect on alexithymia. To explain these findings, one should refer to Whitelather and Doumas' suggested program [33] via which training sessions were conceptualized. Thus it was identified that individual with secure attachment style were 
mentally healthier and more satisfied with their lives. Moreover, according to the definition of intimacy, individuals with lower intimacy may face difficulties in making friendly relationships. Therefore, it seems that those individuals have no proper understanding of their attachment styles. This lack of understanding as well as efforts to control and modify attachment styles can be effective on deficits of their friendly relationships.

\section{Discussion}

Results of the present study indicated that attachment-based therapy training increases the degree of intimacy. Emotional intimacy covers the sharing of positive and negative emotions with spouses. In attachment-based therapy training, the way of formation of attachment and training positive attitudes to oneself via principled training techniques such as familiarity with different attachment styles and their characteristics causes that parents share their positive and negative emotions and feelings with each other via the process of conscious relationships in a secure environment. Sexual intimacy includes sharing thoughts, feelings, and desires with sexual natures. In explaining these findings, it can be said that familiarity with attachment styles and the roles of caregivers and care seekers, the way of practicing those thoughts, and the effects that those trainings have on the way of making relationships lead to increase of intimacy degree in this subscale. In addition, training positive attitudes towards oneself and reducing negative attitudes towards oneself and others finally can enhance sexual intimacy. Social and communication intimacy includes social and communication styles between couples. In explaining the increase in parents' intimacy in this two dimensions, it can be said that, in attachment-based therapy training, marital relationships which is achieved via principled training such as familiarity with one's own styles, individuals' reactions to those whom they love (reactions to others), and reduction in the negative attitudes towards oneself and others results in making relationships between couples and other individuals using a conscious process in an appropriate environment. Training attachment styles were significantly effective on the subscale of spiritual and bodily intimacy. In explaining these findings, the special conditions of the study population, different types of attachment styles training, and the issue that these dimensions of intimacy occur after modifications in the general marital intimacy should be considered. In case of psychological intimacy, the ability of attentions and closeness to spouses were considered. Attachment-based therapy training via training knowledge of one's own attachment style, different attachment styles and their characteristics, caregivers and caregivers' roles, and reactions to others caused more intimacy and closeness to spouses. In the subscale of general intimacy, factors such as closeness of couples to each other, couples' loving each other, understanding souses, etc. which were determined according to training skills such as knowledge of one's own attachment style, different attachment styles and their characteristics, the increase in knowledge, changes in difficult attachment styles, and reactions to others enhanced intimacy [19-21,26,30,31]. Furthermore, according to alexithymia, individuals suffering from emotional disorders are those who face with difficulties in understanding, identifying, and describing their own feelings. Therefore, it seems that those individuals have no appropriate understanding of their own attachment styles. Thus, lack of understanding as well as efforts to control and modify attachment styles can be effective on their emotional disorders.

The findings of the present study are significant in that attachment theory could increase marital satisfaction and intimacy. Insecure attachment styles can be negatively effective on marital relationships and cause the collapse of romantic relationships and marriage. The present study was to probe the effect of attachment-based therapy training on intimacy and alexithymia parents of mentally retarded children. Intimacy can reduce conflicts and 
enhance satisfaction [30], relationships, and marital commitment [5]. The results of the present study are consistent with the results of Botlani Esfahani and Whitelather and Doumas, and Ziv et al. [30,33,38]. There are some implications such as the significant increase in couples' sexual satisfaction and intimacy, prevention from interpersonal problems, and reduction of dangerous sexual behaviors in the present study. Individuals suffering from alexithymia are those who face difficulties in understanding, identification, and description of their own feelings. Therefore, this lack of understanding as well as efforts to control and modify attachment styles can be effective on removal of deficits in friendly relationships among whom?. The significance of the present study was identified with considering the role of attachment styles in lower conflicts, more satisfaction, lower emotional deficits, longer experiences of marital romantic relationships, better relationships with children, better mental health [20], and more support and security [24]. The results of the present study are consistent with the results of previous studies [20] and contains counseling and applied implications.

The results of current investigation suggest attachment-based training workshops for parents of children with special needs. We recommend trainers to have high levels of sympathy with children and make unconditioned relationships with the educational group by consideration of intellectual disability children's special needs. This study has some limitations pertained to sample size that was limited only to parents of intellectual disability children; therefore, the results should be cautiously generalized.

\section{Conclusion}

As a general conclusion, attachment-based therapy training can be significantly effective on intimacy of parents with mentally retarded children; in other words, it can increase intimacy between couples and consequently solve their marital problems. Therefore, their mental health improves and their life expectancy enhances. Moreover, this training makes their perspectives broader. As a result, the parent- child relationships can improve in families.

\section{Acknowledgments}

We are obliged to be greatly thankful of all parents of intellectual disability children participating in the present study.

\section{Contributions}

Study design: AGh, HGh

Data collection and analysis: SA

Manuscript preparation: AGh

\section{Conflicts of Interest}

"The authors declare that they have no competing interest".

\section{Funding}

The author (s) received no financial support for the research, authorship and/or publication of this article.

\section{References}

1- Navabinejad Sh. Marriage Counseling and family therapy. Tehran: Islamic relief society of the Islamic republic of Iran; 2008.

2- Mousavi AS. Permarital counseling. Tehran: Mehr Kavyan; 2007.

3- Afrooz GhA. Psychological principles of Marriage on the bed of Islamic values and culture. Tehran: Tehran university; 2008.

4- Bagarozzi DA. Enhancing intimacy in marriage: A clinician's guide. Translate by: Pour Naghash Tehrani SS, Rezazade MR. Tehran: Al-Zahra university; 2009.

5- Heller PE, Wood B. The process of intimacy: Similarity, understanding and gender. J Marital Fam Ther 1998; 24(3): 273-288.

6- Miller Sh, Miller F, Nanali A, Wakman D. Talking and listening together: couple communication i. Translated by: Bahari F. Tehran: Roshd 2006.

7- Bagarozzi DA. Enhancing intimacy in marriage: a clinicians guide. Teranslate by: Bayat A, Atash Pour SH, Etemadi O. Isfahan: Islamic Azad university of Khorasgan; 2006.

8- Segrin C, Rynes KN. The mediating role of positive relations with others in associations between depressive symptoms, social skills, and perceived stress. J Res Pers2009; 43(6): 962-71.

9- Shah Siyah m. Determine effectiveness of sex education on improve the quality of marital Esfahan. [dissertation]. Family counseling, faculty of educational sciences and psychology, university of Isfahan 2009. 
10- Turnbull AP, Turbiville V, Schaffer R, Schaffer V. "Getting a shot at life" through group action planning. Zero Three 1996; 16(6): 33-40.

11- Malekpour M. Health of family of children with mentally retarded. Esfahan: Jahad Daneshgahi; 1997.

12- Wagner H, Lee V. Alexithymia and individual differences in emotional expression. $J$ Res Pers2008; 42(1): 83-95.

13- Humphreys TP, Wood LM, Parker JDA. Alexithymia and satisfaction in intimate relationships. Pers Individ Dif2009; 46(1): 43-7.

14- Nemiah JC. Alexithymia: present, past--and future? Psychosom Med1996; 58(3): 217-8.

15- Honkalampi K, Saarinen P, Hintikka J, Virtanen V, Viinamäki H. Factors associated with alexithymia in patients suffering from depression. Psychother Psychosom 1999; 68(5): 270-5.

16- Schmidt U, Jiwany A, Treasure J. A controlled study of alexithymia in eating disorders. Compr Psychiatry1993; 34(1): 54-8.

17- Berenbaum H. Childhood abuse, alexithymia and personality disorder. J Psychosom Res1996; 41(6): 585-95. 18- Vanheule S, Desmet M, Meganck R, Bogaerts S. Alexithymia and interpersonal problems. J Clin Psychol2007; 63(1): 109-17.

19- Simon RW. Revisiting the relationships among gender, marital status, and mental health. AJS2002; 107(4): 1065-96. 20-Schmitt DP. Is short-term mating the maladaptive result of insecure attachment? A test of competing evolutionary perspectives. Pers Soc Psychol Bull2005; 31(6): 747-68.

21- Koweleski R, Weston D. Psychology. Exploratory interest in university student. Asian J Soc Psychol2005; 3(11): 302-10

22- Ghasemi H, Jazaieri R, Nedai A, Jahanian M. Investigate the relationship between style attachment with of marital conflict and emotional intelligence, the national Conference of family psychology, University Islamic Azad of Kermanshah. May 26, 2012.

23- Birami M. Predicting marital satisfaction on the basis of attachment styles and differentiation components. Journal of Fundamentals of Mental Health2012; 14(53): 64-77.

24- Berlin LJ, Zeanah CH, Lieberman AF. Prevention and intervention programs for supporting early attachment security. In Cassidy J, Shaver PR, eds. Handbook of attachment: Theory, research, and clinical applications. New York, NY, US: Guilford Press; 2008. pp: 745-61.

25- Kauhanen J, Kaplan GA, Julkunen J, Wilson TW, Salonen JT. Social factors in alexithymia. Compr Psychiatry1993; 34(5): 330-5.

26- Weinryb RM, Gustavsson JP, Hellström C, Andersson
E, Broberg A, Gunnar R. Interpersonal problems and personality characteristics: Psychometric studies of the Swedish version of the IIP. Pers Individ Dif1996; 20(1): 13-23.

27- Kokkonen P1, Karvonen JT, Veijola J, et al. Prevalence and sociodemographic correlates of alexithymia in a population sample of young adults. Compr Psychiatry2001; 42(6): 471-6.

28- Sibley CG. The association between working models of attachment and personality: toward an integrative framework operationalizing global relational models. $J$ Res Pers2007; 41(1): 90-109.

29- Fuller ML, Olsen G. Home-school relations: Working successfully with parents and families. Boston, US: Allyn \& Bacon; 1998.

30- Botlani Esfahani S. impact of Couples therapy based on of attachment theory on the sexual satisfaction and sexual intimacy couples city of Isfahan, The family Counseling. [Thesis]. University of Esfahan, faculty of education and psychology 2008.

31- Gall M, Borg W, Gall J. Qualitative and quantitative of research in the Educational Sciences and psychology methods. Translate by Nasser AR. Tehran: Samt; 2011. 32- Molavi H. Practical Guide to SPSS 10- 13- 14 in the Behavioral Sciences. Tehran: Pooyesh Andisheh Publication; 2013.

33- Whiteleather A, Doumas D. The Relationship Between Adult Attachment Style and Sexual Attitudes. InPresentato al Midwestern Psychological Association Annual Conference. Apr, 2004. Boise: Idaho.

34- Oliya N, Fatehizadeh M, Bahrami F. Effect marital life enrichment teaching of an increase marital intimacy. Journal of Family Research2006; 2(6): 119-135.

35- Besharat MA. Psychometric characteristics of Persian Version of the Toronto Alexithymia Scale-20 in clinical and non-clinical samples. Iran J Med Sci2008; 33(1): 1-6.

36- Bagby RM, Parker JDA, Taylor GJ. The twentyitem Toronto Alexithymia scale-I. Item selection and cross-validation of the factor structure. J Psychosom Res 1994; 38(1): 23-32.

37- Pourhosein R, Rostami R, Besharat MA, Mirzamani M. Assessing reliability and validity of Farsi version of the Toronto Alexithymia Scale-20 in a sample of opioid substance use disordered patients. Iran $J$ Psychiatry2006; 1(4): 133- 9.

38- Berlin LJ, Ziv L, Amaya-Jackson MT. Enhancing early Attachments: theory, research, intervention, and policy. Duke Series in Child Development and Public Policy. Guildford Press: New York, NY, 2005.

\footnotetext{
Copyright (C) 2016 ASP Ins. This open-access article is published under the terms of the Creative Commons Attribution-NonCommercial 4.0 International License which permits Share (copy and redistribute the material in any medium or format) and Adapt (remix, transform, and build upon the material) under the Attribution-NonCommercial terms.
} 